University of Nebraska - Lincoln

DigitalCommons@University of Nebraska - Lincoln

Marjorie A. Langell Publications

Published Research - Department of Chemistry

7-1-1999

Nickelocene adsorption on single-crystal surfaces

D. L. Pugmire

University of Nebraska-Lincoln, pugmire@ornl.gov

C. M. Woodbridge

University of Nebraska - Lincoln, cwoodbridge@ggc.edu

S. Root

University of Nebraska - Lincoln

Marjorie Langell

University of Nebraska - Lincoln, mlangell1@unl.edu

Follow this and additional works at: https://digitalcommons.unl.edu/chemistrylangell

Part of the Chemistry Commons

Pugmire, D. L.; Woodbridge, C. M.; Root, S.; and Langell, Marjorie, "Nickelocene adsorption on singlecrystal surfaces" (1999). Marjorie A. Langell Publications. 4.

https://digitalcommons.unl.edu/chemistrylangell/4

This Article is brought to you for free and open access by the Published Research - Department of Chemistry at DigitalCommons@University of Nebraska - Lincoln. It has been accepted for inclusion in Marjorie A. Langell Publications by an authorized administrator of DigitalCommons@University of Nebraska - Lincoln. 


\title{
Nickelocene adsorption on single-crystal surfaces
}

\author{
D. L. Pugmire and C. M. Woodbridge \\ Departments of Chemistry and Center for Materials Research and Analysis, University of Nebraska- \\ Lincoln, Lincoln, Nebraska 68588-0304
}

S. Root

Departments of Physics and Center for Materials Research and Analysis, University of Nebraska-Lincoln, Lincoln, Nebraska 68588-0304

M. A. Langella)

Department of Chemistry and Center for Materials Research and Analysis, University of Nebraska-Lincoln, Lincoln, Nebraska 68588-0304

(Received 12 October 1998; accepted 26 April 1999)

\begin{abstract}
Nickelocene adsorption onto $\mathrm{Ag}(100), \mathrm{Ni}(100)$, and $\mathrm{NiO}(100) / \mathrm{Ni}(100)$ surfaces was studied with $\mathrm{x}$-ray photoelectron spectroscopy and high-resolution electron energy loss spectroscopy at $135 \mathrm{~K}$ for monolayer and multilayer coverages of $\mathrm{NiCp}_{2}$. On the relatively inert $\mathrm{Ag}(100)$ surface, nickelocene physisorbs molecularly, with its molecular axis perpendicular to the surface plane. Exposure to the reactive $\mathrm{Ni}(100)$ surface results in the decomposition of nickelocene into acetylene and acetylene-like fragments and, when this surface is warmed to $273 \mathrm{~K}$, carbide contamination is observed. There is evidence for double-bond carbon on nickelocene-exposed $\mathrm{NiO}(100)$, and vinyl and propenyl fragments are the most likely decomposition products on this surface. At very large exposures, adsorbed nickelocene is molecularly condensed and, therefore, produces similar thin films on all three surfaces. (C) 1999 American Vacuum Society. [S0734-2101(99)20904-9]
\end{abstract}

\section{INTRODUCTION}

The adsorption and subsequent decomposition of metallocenes at solid substrates are of interest to their proposed use as source molecules for the selective area deposition of metals. ${ }^{1-12}$ Ferrocene, which is prototypical of the metallocenes, is generally very stable to thermal decomposition. Studies of ferrocene $\left(\mathrm{FeCp}_{2} ; \mathrm{Cp}=\right.$ cyclopentadienyl $)$ adsorbed onto several different substrates have been reported $^{1,3-8,12}$ and, for many of these, ferrocene is observed to adsorb molecularly but to undergo decomposition to lose cyclopentadiene under electron or photon irradiation at low temperatures. Warming the ferrocene-covered substrate to $\geq 200 \mathrm{~K}$ allows the material to desorb cleanly from areas that were not irradiated while depositing metal with features as small as $50 \AA$ in the irradiated areas. ${ }^{3}$

Extension of this process to metallocenes containing more useful metals is desirable, but few studies have been reported for these materials to date. We present here adsorption studies of nickelocene $\left(\mathrm{NiCp}_{2}\right)$ on $\mathrm{Ag}(100), \mathrm{Ni}(100)$, and $\mathrm{NiO}(100)$ surfaces, which span a range of reactivity in nickelocene decomposition. Nickelocene, with its 20 electron ligand valence shell, can be anticipated to be more reactive than the 18 electron ferrocene. The $\mathrm{Ag}(100)$ surface was chosen for investigation because it was expected to be relatively inert to metallocene decomposition. The quite reactive $\mathrm{Ni}(100)$ surface was studied as well. Finally, the $\mathrm{NiO}(100)$ surface with a reactivity anticipated to be intermediate between the other substrates was investigated. This last surface is also interesting because it is an insulating material, whereas the other surfaces are conductors.

${ }^{a)}$ Electronic mail: mlangell@unlinfo.unl.edu

\section{EXPERIMENT}

$\operatorname{Ag}(100)$ and $\mathrm{Ni}(100)$ single crystals were obtained from Goodfellow, oriented to within $0.5^{\circ}$ of the (100) plane and polished to a mirror finish with $0.3 \mu \mathrm{m}$ diamond paste. $\mathrm{NiO}(100)$ was grown as a thin film upon the $\mathrm{Ni}(100)$ substrate. Each metal substrate was mounted on a manipulator capable of resistive heating and liquid-nitrogen cooling, as described previously, ${ }^{9}$ and the temperature of the sample was monitored with a type- $K$ thermocouple (chromel-alumel). The manipulator was then placed into ultrahigh vacuum (UHV) in a stainless-steel bell jar equipped with Auger electron (AES) and $x$-ray photoelectron (XPS) spectroscopies, low-energy electron diffraction (LEED), and high-resolution electron energy loss spectroscopy (HREELS). While Auger spectroscopy could be used to monitor the clean substrates, exposure of nickelocene-covered surfaces to the AES primary electron beam resulted in electron-induced decomposition. Therefore, information on surface coverage was restricted to that obtained with XPS techniques. No x-ray or electron-induced decomposition of the metallocene was obvious during acquisition of XPS or HREELS data.

The $\operatorname{Ag}(100)$ sample was cleaned by repeated cycles of sputtering with $\mathrm{Ar}^{+}(0.5 \mathrm{keV}$ and $25 \mathrm{~mA})$ at $623 \mathrm{~K}$ for 15 min followed by annealing under UHV at $673 \mathrm{~K}$ for $20 \mathrm{~min}$ until no impurities could be detected by AES. The Ni(100) sample was cleaned by repeated cycles of sputtering with $\mathrm{Ar}^{+}(0.5 \mathrm{keV}$ and $25 \mathrm{~mA})$ at room temperature for $15 \mathrm{~min}$, annealing under oxygen $\left(1 \times 10^{-7}\right.$ Torr $)$ for $15 \mathrm{~min}$ at $623 \mathrm{~K}$ and UHV annealing at $873 \mathrm{~K}$ for $5 \mathrm{~min}$, similar to a previously reported cleaning procedure for $\mathrm{Ni}(100) .{ }^{13}$ The latter cleaning procedure was also used to prepare the surface for the growth of the $\mathrm{NiO}(100)$ thin film. The clean $\mathrm{Ni}(100)$ 
surface was then exposed to $600 \mathrm{~L}\left(5 \times 10^{-7}\right.$ Torr, $\left.20 \mathrm{~min}\right)$ of $\mathrm{O}_{2}$ and the substrate flashed to $573 \mathrm{~K}$ to convert the metastable $\mathrm{NiO}(111)$ to a $\mathrm{NiO}(100)$ film. ${ }^{13}$ This dosing/heating procedure was repeated two more times to maximize the order and thickness of the film.

The clean surfaces were dosed by the admission of nickelocene vapor into the chamber through a standard leak valve equipped with a needle doser that concentrated the vapor in the vicinity of the sample crystals. During crystal exposure to $\mathrm{NiCp}_{2}$ and the subsequent adsorbate analysis, crystal temperatures were maintained at $135 \mathrm{~K}$ unless otherwise noted. Exposures are reported in Langmuirs (L) and details of the doser time to langmuir calibration procedure can be found in Ref. 9.

XPS was performed with $\mathrm{Mg} K \alpha$ radiation $(1253.6 \mathrm{eV}$ ) and a Physical Electronics model 15-255 G double-pass cylindrical mirror analyzer operating in the constant pass energy, pulse-count mode. A pass energy of $50 \mathrm{eV}$ was used during data collection. The binding energies were calibrated by reference to substrate transitions: $367.9 \mathrm{eV}$ for $\mathrm{Ag} 3 d_{5 / 2}$, 852.3 for $\mathrm{Ni} 2 p_{3 / 2}$, and $529.4 \mathrm{eV}$ for $\mathrm{O} 1 s$ in $\mathrm{NiO}$.

The high-resolution electron energy loss spectra were obtained using a LK-2000 spectrometer, a double-pass $127^{\circ}$ sector electrostatic analyzer with variable detection angle capabilities. The primary electron beam was incident to the surfaces at $60^{\circ}$ relative to the surface normal with a beam energy of $3.77 \mathrm{eV}$ and a current of approximately $70 \mathrm{pA}$. The typical full width at half maximum (FWHM) for the spectra obtained ranged from 4 to $8 \mathrm{meV}$. A crystal bias of $-1.7 \mathrm{eV}$ was used in obtaining data on $\mathrm{Ni}(100)$ and $\mathrm{NiO}(100)$ substrates to ensure an adequate signal-to-noise ratio. No crystal bias was needed for $\operatorname{Ag}(100)$ measurements and the sample was simply grounded to the UHV chamber which served as common ground in the HREELS studies.

\section{RESULTS AND DISCUSSION}

\section{A. $\operatorname{Ag}(100)$}

The vibrational spectrum of nickelocene adsorbed onto the $\operatorname{Ag}(100)$ substrate is shown in Fig. 1. Figure 1(b) contains the on and off specular HREELS data for high nickelocene exposures of $1500 \mathrm{~L}$. The loss energies and assignments for all systems exhibiting molecular adsorption are listed in Table I. The spectrum is similar to infrared (IR) and Raman data previously reported for molecular nickelocene. ${ }^{14}$ Thus as expected, at high exposures adsorbed nickelocene is a multilayered film of condensed material with surface properties exhibited by bulk $\mathrm{NiCp}_{2}$. XPS measurements yield binding energies of $284.6 \mathrm{eV}$ for the $\mathrm{C} 1 s$ transition and $854.6 \mathrm{eV}$ for the $\mathrm{Ni} 2 p_{3 / 2}$ transition, in good agreement with literature values for molecular nickelocene. ${ }^{15}$

Figure 1(a) shows the on and off specular HREEL spectra for one monolayer of $\mathrm{NiCp}_{2}$ interacting directly with the $\mathrm{Ag}(100)$ surface, produced by exposure to $11 \mathrm{~L}$ nickelocene at $135 \mathrm{~K}$. The on specular spectrum shows modes at energies which are relatively unperturbed from vibrational modes observed for molecular $\mathrm{NiCp}_{2}$ (Ref. 14) and for the multilayer
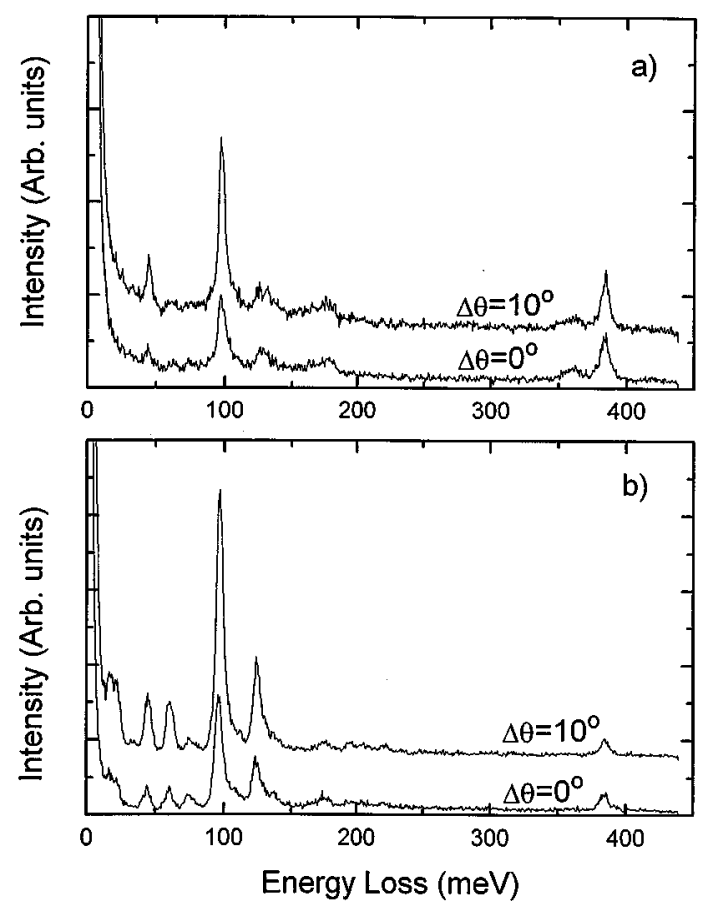

FIG. 1. Electron energy loss spectra of $\mathrm{Ag}(100)$ at $135 \mathrm{~K}$ exposed to (a) 11 $\mathrm{L}$ and (b) $1500 \mathrm{~L}$ of nickelocene. At high coverages the modes at 16.5 and $124.4 \mathrm{meV}$ show an increase in relative intensity.

spectrum of Fig. 1(b). C $1 s$ and Ni $2 p_{3 / 2}$ XPS data, shown in Fig. 2, are found at 284.6 and $854.6 \mathrm{eV}$, respectively, and identical to binding energies obtained on the multilayer nickelocene condensate. The $\mathrm{C} 1 s / \mathrm{Ni} 2 p_{3 / 2}$ intensity ratio for the $\mathrm{NiCp}_{2}$ monolayer is 0.35 , which correlates with a $10 / 1 \mathrm{C} / \mathrm{Ni}$ atomic ratio when differences in the relative XPS cross sections are taken into account. ${ }^{16}$ Upon warming the $\mathrm{NiCp}_{2}$-covered $\mathrm{Ag}(100)$ substrate, the adsorbate desorbs cleanly to yield no carbon or nickel detectable by AES at 273 $\mathrm{K}$. Thus, at the monolayer level, nickelocene is physisorbed on $\operatorname{Ag}(100)$ with no molecular decomposition evident.

Orientational information can be obtained on the molecular nickelocene by comparing on and off specular HREELS intensities. In the more stable staggered ring configuration, the nickelocene molecule belongs to the $D_{5 d}$ point group in which vibrational modes with $A_{2 u}$ or $E_{1 u}$ symmetries are expected to be dipole active. If the molecular axis of nickelocene is taken to be along the $z$ direction, modes with $E_{1 u}$ symmetry will be polarized in the $x y$ plane and $A_{2 u}$ modes will be polarized along the $z$ axis. Depending on the orientation of the adsorbed molecules with respect to the surface, some or all of these potentially observable modes are also predicted to be dipole active by surface dipole selection rules, depending upon the orientation of the $z$ axis with respect to the surface normal.

There are four characteristic modes which are particularly useful for the determination of the orientation of adsorbed nickelocene on the $\operatorname{Ag}(100)$ surface. The first of these modes is the ring-metal-ring bending mode with $E_{1 u}$ symmetry. The second is the asymmetric ring-metal-ring stretch, $\nu_{\text {as }}(\mathrm{RMR})$, with $A_{2 u}$ symmetry. The third is a mode in which $\mathrm{C}-\mathrm{H}$ bend- 
TABLE I. Energy losses and assignments for the molecular adsorption of nickelocene on various surfaces.

\begin{tabular}{|c|c|c|c|c|}
\hline Molecular nickelocene & $\begin{array}{c}\operatorname{Ag}(100)- \\
\text { monolayer } \\
\mathrm{meV}\left(\mathrm{cm}^{-1}\right)\end{array}$ & $\begin{array}{c}\mathrm{Ag}(100)- \\
\text { multilayer } \\
\mathrm{meV}\left(\mathrm{cm}^{-1}\right)\end{array}$ & $\begin{array}{c}\mathrm{Ni}(100)- \\
\text { multilayer } \\
\mathrm{meV}\left(\mathrm{cm}^{-1}\right)\end{array}$ & $\begin{array}{c}\mathrm{NiO}(100)- \\
\text { multilayer } \\
\mathrm{meV}\left(\mathrm{cm}^{-1}\right)\end{array}$ \\
\hline $\mathrm{R}-\mathrm{M}-\mathrm{R}$ bend & N.R. ${ }^{a}$ & $16.5(133)$ & N.R. & N.R. \\
\hline $\mathrm{R}-\mathrm{M}-\mathrm{R}$ asymmetric stretch & $45.1(364)$ & $44.5(359)$ & $45.7(369)$ & $45.1(364)$ \\
\hline Ring deformation ${ }^{\mathrm{b}}$ & $61.0(492)$ & $60.4(487)$ & $60.4(487)$ & N.R. \\
\hline Fuchs-Kliewer phonon & & & & $66.5(536)$ \\
\hline $\mathrm{C}-\mathrm{H}$ bend $(\perp)$ & $96.9(781)$ & $97.0(782)$ & $96.9(781)$ & $96.3(777)$ \\
\hline $\mathrm{C}-\mathrm{H}$ bend $(\|)$ & $123.8(998)$ & $124.4(1003)$ & $125.0(1008)$ & $125.0(1008)$ \\
\hline Asymmetric C-C stretch & $176.8(1426)$ & $173.9(1403)$ & $176.2(1421)$ & $176.8(1426)$ \\
\hline $\mathrm{C}-\mathrm{H}$ stretch & $\begin{array}{l}386.7(3119) \\
360.3(2906)\end{array}$ & $384.3(3099)$ & $385.3(3107)$ & $384.7(3103)$ \\
\hline
\end{tabular}

${ }^{\mathrm{a} N}$.R. indicates modes that were not resolved.

${ }^{\mathrm{b}}$ Tenative assignment.

ing occurs perpendicular to the plane of the rings with $A_{2 u}$ symmetry. The fourth is an additional $\mathrm{C}-\mathrm{H}$ bending mode, with the motion in the plane of the rings in $E_{1 u}$ symmetry. Literature IR values for the energies of these modes are 15.5, $44.0,95.9$, and $124.0 \mathrm{meV}\left(125,355,773,1000 \mathrm{~cm}^{-1}\right)$, respectively. ${ }^{14}$ At one monolayer coverage of $\mathrm{NiCp}_{2}$ on $\operatorname{Ag}(100)$, all of these modes, except the ring-metal-ring bending mode, are observed.

Comparison of on and off specular data shows that the two modes with $A_{2 u}$ symmetry are dipole active by the dramatic loss of intensity at $10^{\circ}$ off specular. The observed mode with $E_{1 u}$ symmetry is considerably less intense than the dipole modes on specular, and does not change significantly in intensity as the detection angle is moved off specular. The off specular behavior of this mode and the lack of

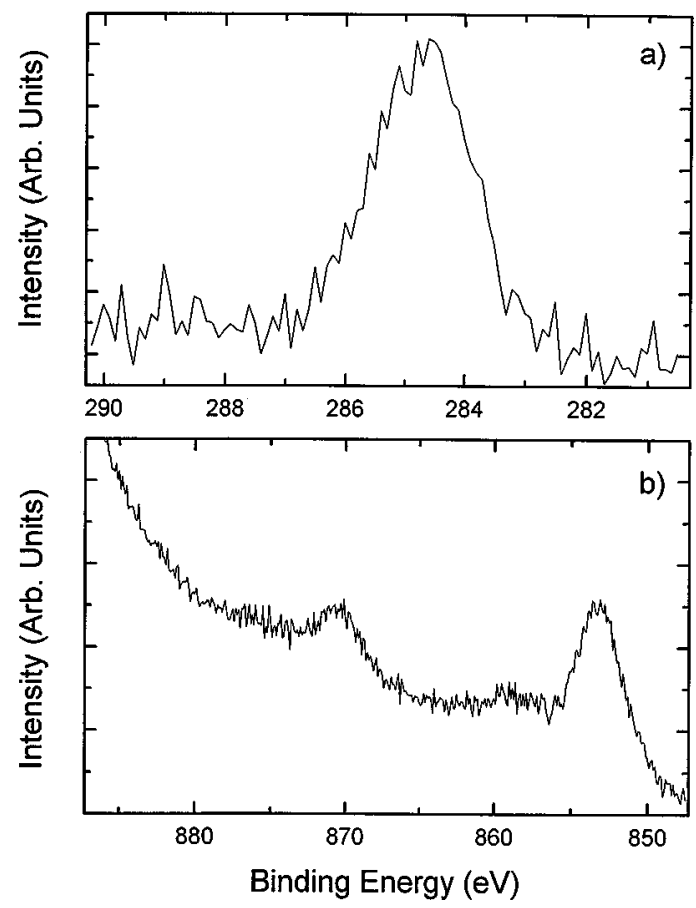

FIG. 2. XP spectra of one monolayer of nickelocene on $\operatorname{Ag}(100)$ at $135 \mathrm{~K}$. (a) $\mathrm{C} 1 s$ and (b) Ni $2 p$ regions. intensity of the two $E_{1 u}$ modes is evidence that vibrations with this symmetry must be oriented parallel to the surface plane. This indicates that nickelocene molecules on a $\mathrm{Ag}(100)$ surface at $135 \mathrm{~K}$ are adsorbed with the molecular axis perpendicular, or very nearly perpendicular, to the surface.

The intensities of all the modes observed at one monolayer increase as the exposure to nickelocene is increased. However, the two modes with $E_{1 u}$ symmetry show a more dramatic increase in intensity than the other modes observed in the HREEL spectrum. At high coverages, the $\nu_{\text {as }}(\mathrm{RMR})$ and the perpendicular $\mathrm{C}-\mathrm{H}$ bending modes are observed as intense losses, as found for monolayer-covered $\operatorname{Ag}(100)$. Unlike the monolayer spectrum, the ring-metal-ring bending and in-plane $\mathrm{C}-\mathrm{H}$ bending modes are also observed as intense losses at 16.5 (133) and $124.4 \mathrm{meV}\left(1003 \mathrm{~cm}^{-1}\right)$, respectively. All four modes, with $A_{2 u}$ or $E_{1 u}$ symmetry, are dipole active in multilayer spectra, as seen when comparing the on specular data with that obtained off specular. Thus, at high coverages, the molecular axis of adsorbed nickelocene is neither strictly perpendicular to the surface, as it is for monolayer coverage, nor is it parallel to the surface but is at some intermediate angle.

\section{B. $\mathrm{Ni}(100)$}

With long exposures of nickelocene to the $\mathrm{Ni}(100)$ substrate at $135 \mathrm{~K}$, the HREEL spectrum [Fig. 3(b)] of the multilayer condensate resembles that of molecular nickelocene, as is found above for $\mathrm{Ag}(100)$. After exposure of the $\mathrm{Ni}(100)$ surface to $1200 \mathrm{~L}$ of nickelocene, the spectrum has many of the same features of Fig. 1(b), with the intense $\nu_{\text {as }}(\mathrm{RMR})$, perpendicular $\mathrm{C}-\mathrm{H}$ bending, and parallel $\mathrm{C}-\mathrm{H}$ bending modes observed at 45.7 (369), 96.9 (781), and 125.0 $\mathrm{meV}\left(1008 \mathrm{~cm}^{-1}\right)$, respectively. The photoelectron binding energies are similar to those seen in previous XPS data, with the $\mathrm{C} 1 s$ transition at $284.5 \mathrm{eV}$. Photoemission from Ni $2 p_{3 / 2}$ core level of the nickelocene is not resolvable from the much stronger signal of the $\mathrm{Ni}(100)$ substrate.

A profound difference is seen, however, in the low coverage vibrational spectrum of nickelocene on $\mathrm{Ni}(100)$, which is evidently a more reactive substrate in metallocene decom- 


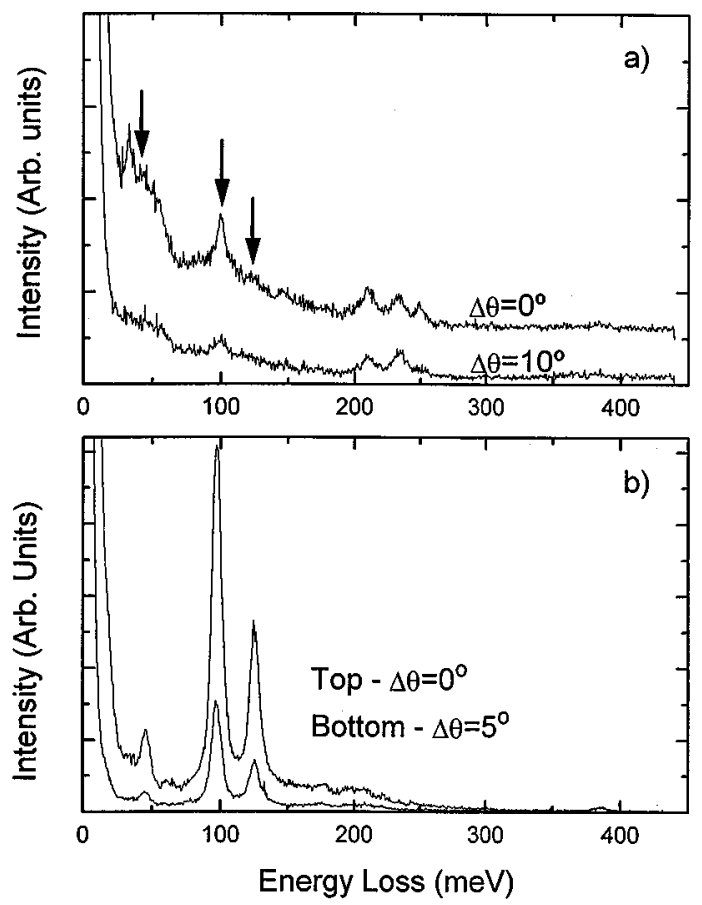

FIG. 3. Electron energy loss spectra of $\mathrm{Ni}(100)$ at $135 \mathrm{~K}$ exposed to (a) $8 \mathrm{~L}$ and (b) $1200 \mathrm{~L}$ of nickelocene. The low coverage spectra show considerable decomposition. The arrows indicate the losses due to nickelocene vibrational modes.

position than is the $\operatorname{Ag}(100)$ surface. Figure 3(a) shows the on and off specular HREEL spectra of the $\mathrm{Ni}(100)$ surface at $135 \mathrm{~K}$ exposed to $8 \mathrm{~L}$ of $\mathrm{NiCp}_{2}$. Tentative spectral assignments for systems showing nickelocene decomposition are given in Table II. The three losses indicated with arrows in Fig. 3(a), occur at comparable energies to those observed for molecular nickelocene; thus there is some molecularly adsorbed $\mathrm{NiCp}_{2}$ present on this surface. These modes are located at 43.3 (349), 100.0 (807), and $121.9 \mathrm{meV}\left(983 \mathrm{~cm}^{-1}\right)$ and are due to the $\nu_{\text {as }}(\mathrm{RMR}), \mathrm{C}-\mathrm{H}$ bend $(\perp)$, and $\mathrm{C}-\mathrm{H}$ bend (II) vibrations of the nickelocene molecule. These modes are shifted slightly from multilayer nickelocene and from monolayer nickelocene on $\operatorname{Ag}(100)$, which may be an indication that the adsorbate may be interacting more strongly on $\mathrm{Ni}(100)$. However, these modes belong to an adsorbate species that is still essentially molecular $\mathrm{NiCp}_{2}$.

Three new losses appear in the monolayer spectrum and are observed in the $200-250 \mathrm{meV}\left(1613-2016 \mathrm{~cm}^{-1}\right)$ range. This energy region is dominated by the stretching modes of $\mathrm{CO}$, which may result from background contamination, and by species containing carbon-carbon triple bonds. No other possible adsorbate species that could potentially form from metallocene decomposition at $135 \mathrm{~K}$ is commonly encountered in this region. The mode observed at $249.4 \mathrm{meV}$ (2011 $\mathrm{cm}^{-1}$ ) is dipole active and is most likely due to CO. The $\nu_{\mathrm{CO}}$ loss has previously been reported as $253.8 \mathrm{meV}\left(2047 \mathrm{~cm}^{-1}\right)$ on $\mathrm{Ni}(100){ }^{17}$

The remaining two modes in this region, at 209.7 (1691) and $234.1 \mathrm{meV}\left(1888 \mathrm{~cm}^{-1}\right)$, which are not dipole active, are due to $\nu_{\mathrm{CC}}$ modes of acetylene or acetylene-like fragments that have strong $\mathrm{C}-\mathrm{C}$ triple bond character. While exact identification of these species awaits more detailed HREELS and thermal desorption analysis, tentative assignments can be made by comparison of loss energies with those of IR spectra from organometallic compounds. In nickel coordination compounds, the stretching energies of carbon-carbon triple bond-containing ligands have been shown to fall in the 230-270 meV (1855-2178 $\left.\mathrm{cm}^{-1}\right)$ region, with larger substituent groups having higher vibrational loss energies. ${ }^{18}$ The lower of the two $\nu(\mathrm{C} \equiv \mathrm{C})$ losses is assigned to acetylene. Several metal complexes with $\pi$-bonded acetylenic groups have been reported with the $\mathrm{C}-\mathrm{C}$ stretching energy in the region of $200-220 \mathrm{meV}\left(1613-1774 \mathrm{~cm}^{-1}\right){ }^{19}$ The higher $\nu(\mathrm{C} \equiv \mathrm{C})$ loss is assigned to propyne or a propyne-like fragment which contains a $\mathrm{CH}_{x}$ substituent attached to one of the triple-bonded carbons. It, therefore, appears that on the $\mathrm{Ni}(100)$ surface the cyclopentadienyl ligand is decomposing into $\mathrm{C}_{2} \mathrm{H}_{x}$ and $\mathrm{C}_{3} \mathrm{H}_{x}$ acetylene-like fragments. The loss observed at $144.5 \mathrm{meV}\left(1165 \mathrm{~cm}^{-1}\right)$ in Fig. 3(a) is due to a $\nu_{\mathrm{CC}}$ mode of a carbon-carbon single bond, ${ }^{20}$ and is assigned to the species giving rise to the higher energy $\nu(\mathrm{C} \equiv \mathrm{C})$ found at $234.1 \mathrm{meV}\left(1888 \mathrm{~cm}^{-1}\right)$. The losses at $34.1(275)$ and 54.3 $\mathrm{meV}\left(438 \mathrm{~cm}^{-1}\right)$ are typical of metal-carbon stretches. The

TABLE II. Energy losses and assignments for decomposition fragments following the adsorption of nickelocene on $\mathrm{Ni}(100)$ and $\mathrm{NiO}(100)$ at $135 \mathrm{~K}$.

\begin{tabular}{lclc}
\hline \hline \multicolumn{1}{c}{$\mathrm{Ni}(100)-8 \mathrm{~L}$} & $\mathrm{meV}\left(\mathrm{cm}^{-1}\right)$ & $\mathrm{NiO}(100)-10 \mathrm{~L}$ & $\mathrm{meV}\left(\mathrm{cm}^{-1}\right)$ \\
\hline $\mathrm{M}-\mathrm{C}$ stretch & $34.1(275)$ & $\mathrm{M}-\mathrm{C}$ stretch & $38.4(310)$ \\
$\mathrm{R}-\mathrm{M}-\mathrm{R}$ asymmetric & $43.3(349)$ & 1st NiO phonon loss & $67.1(541)$ \\
stretch $\left(\mathrm{NiCp}_{2}\right)$ & & & \\
$\mathrm{M}-\mathrm{C}$ stretch & $54.3(438)$ & $\mathrm{C}-\mathrm{C}$ stretch of propenyl & $115.2(929)$ \\
$\mathrm{C}-\mathrm{H}$ bend $\left(\mathrm{NiCp}_{2}\right)(\perp)$ & $100.0(807)$ & 2nd NiO phonon loss & $129.8(1047)$ \\
$\mathrm{C}-\mathrm{H}$ bend $\left(\mathrm{NiCp}_{2}\right)(\|)$ & $121.9(983)$ & $\mathrm{C}=\mathrm{C}$ stretch (vinyl and & $193.5(1561)$ \\
& & propenyl $)^{\mathrm{a}}$ & \\
$\mathrm{C}-\mathrm{C}$ stretch (propyne) & $144.5(1165)$ & $\mathrm{C}-\mathrm{H}$ stretch & $383.5(3093)$ \\
$\mathrm{C} \equiv \mathrm{C}$ stretch (acetylene) & $209.7(1691)$ & & \\
$\mathrm{C} \equiv \mathrm{C}$ stretch (propyne) & $234.1(1888)$ & & \\
$\mathrm{C} \equiv \mathrm{O}$ stretch & $249.4(2011)$ & & \\
$\mathrm{C}-\mathrm{H}$ stretch & $383.5(3093)$ & & \\
\hline \hline
\end{tabular}

${ }^{\text {aThis loss occurs in the region of the } 3 \mathrm{rd} \mathrm{NiO} \text { phonon loss, therefore it is difficult to accurately determine the }}$ energy. 

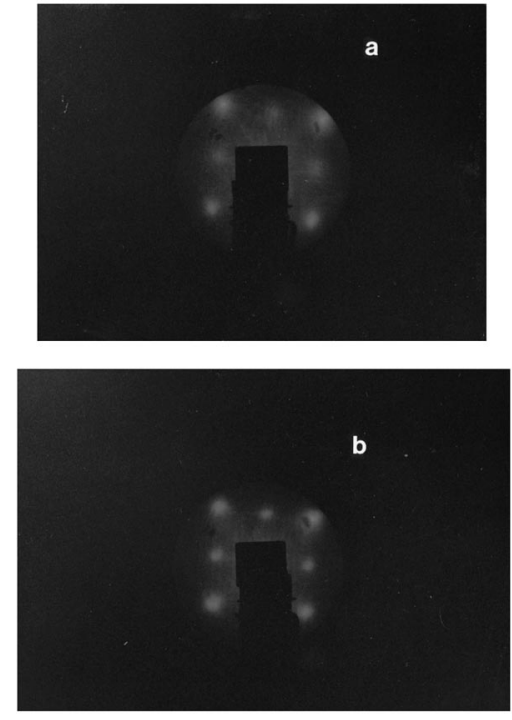

FIG. 4. LEED patterns of (a) the clean $\mathrm{Ni}(100)$ surface and (b) the $\mathrm{NiO}(100)$ thin film. Both pictures are taken with an incident energy of $69.8 \mathrm{eV}$.

$\nu_{\mathrm{MC}}$ is reported at $28.5(230)$ and $53.3 \mathrm{meV}\left(430 \mathrm{~cm}^{-1}\right)$ for acetylene adsorbed on $\mathrm{Ni}(100) .^{21}$

Despite the differences in the vibrational spectra upon moving to a more reactive surface, the binding energies seen with XPS are indistinguishable from those of molecular nickelocene. The carbon $1 s$ transition is located at $284.3 \mathrm{eV}$ and the energy of the nickel $2 p_{3 / 2}$ transition cannot be determined because of the large intensity of this transition in the substrate. The similarity of the XP spectra of the molecularly adsorbed nickelocene on $\mathrm{Ag}(100)$ and the decomposition products of nickelocene on $\mathrm{Ni}(100)$ is expected because of the difficulty in differentiating aromatic from aliphatic carbon with XPS.

AES data of the surface after it was heated to $273 \mathrm{~K}$ indicated the presence of carbon. The carbon line shape in the differentiated spectrum was characteristic of a carbide. ${ }^{22}$ A small peak occurring at $283.7 \mathrm{eV}$ was observed in the XPS data of the heated surface. The lower than typical binding energy of this carbon $1 s$ XPS data also indicates the presence of a carbide. ${ }^{16}$

\section{C. $\mathrm{NiO}(100)$}

$\mathrm{NiO}(100)$ was formed as a thin, crystalline film on the $\mathrm{Ni}(100)$ substrate. The growth and surface characteristics of $\mathrm{Ni}(100) / \mathrm{NiO}(100)$ thin film substrates have previously been well studied. ${ }^{13,23-27}$ The growth of the ordered thin film of $\mathrm{NiO}(100)$ on the $\mathrm{Ni}(100)$ substrate was monitored with several techniques. HREELS was used to detect the characteristic Fuchs-Kliewer phonon at $69.6 \mathrm{meV}\left(561 \mathrm{~cm}^{-1}\right)^{13} \mathrm{de}-$ scribed more fully below. Upon growth of the $\mathrm{NiO}$ thin film, XPS showed the characteristic shift of the $\mathrm{Ni} 2 p_{3 / 2}$ peak to $853.3 \mathrm{eV}$, an increase in the $\mathrm{Ni} 2 p_{3 / 2}$ satellite peak intensity, and the appearance of an $\mathrm{O} 1 s$ photoelectron peak set to $529.4 \mathrm{eV}$ by the calibration procedure. Figure 4 shows LEED patterns obtained of (a) the $\mathrm{Ni}(100)$ substrate and (b) the
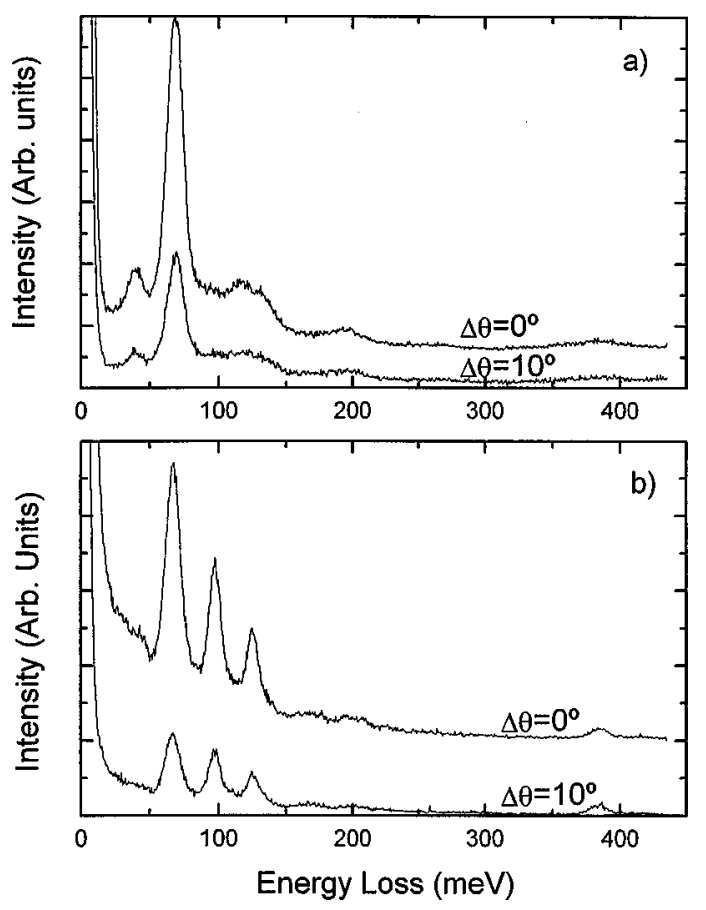

FIG. 5. Electron energy loss spectra of $\mathrm{Ni}(100) / \mathrm{NiO}(100)$ at $135 \mathrm{~K}$ exposed to (a) $10 \mathrm{~L}$ and (b) $600 \mathrm{~L}$ of nickelocene. The intense loss at $67.1 \mathrm{meV}$ is due to the Fuchs-Kliewer phonon of the metal oxide thin film.

$\mathrm{NiO}(100)$ thin film grown on the substrate. The reciprocal lattice spacing decreases for the oxide film, as expected, and the oxide film is thick enough to attenuate detection of the $\mathrm{Ni}(100)$ substrate in both XPS and LEED.

As found for multilayer nickelocene above, the vibrational spectrum taken after a high exposure of $\mathrm{NiCp}_{2}$ resembles the condensed-film, molecular spectra. The HREEL spectrum of the $\mathrm{NiO}(100)$ thin film at $135 \mathrm{~K}$ exposed to 600 $\mathrm{L}$ of nickelocene is shown in Fig. 5(b). The $\nu_{\text {as }}(\mathrm{RMR})$ mode at $45.1 \mathrm{meV}\left(364 \mathrm{~cm}^{-1}\right)$ appears as a small shoulder to the elastic peak. The intense mode at $66.5 \mathrm{meV}\left(536 \mathrm{~cm}^{-1}\right)$ is due to $\mathrm{NiO}$ phonon loss and those at $96.3\left(777 \mathrm{~cm}^{-1}\right)$ and $125.0 \mathrm{meV}\left(1008 \mathrm{~cm}^{-1}\right)$ are due to the perpendicular and parallel $\mathrm{C}-\mathrm{H}$ bending modes, respectively. XPS gives a carbon $1 s$ binding energy of $284.5 \mathrm{eV}$, similar to data from high exposures to the other surfaces and to molecular nickelocene values. $^{15}$

Adsorption of $\mathrm{NiCp}_{2}$ on the $\mathrm{NiO}(100)$ thin film yields different results than found for either $\mathrm{Ag}(100)$ or $\mathrm{Ni}(100)$ substrates. The HREEL spectra obtained from the NiO(100)/ $\mathrm{Ni}(100)$ substrate exposed to $10 \mathrm{~L}$ of nickelocene are shown in Fig. 5(a). The peaks occurring at 67.1 (541) and 129.8 $\mathrm{meV}\left(1047 \mathrm{~cm}^{-1}\right)$ are due to single and double energy Fuchs-Kliewer phonon losses of the nickel oxide substrate. The possibility of triple phonon loss, anticipated at approximately $200 \mathrm{meV}\left(1613 \mathrm{~cm}^{-1}\right)$ but with considerably less intensity than the second phonon loss, unfortunately complicates the assignment of cyclopentadienyl surface fragments in this region. Despite these limitations, decomposition is clearly evident in the HREEL spectrum by the lack of the characteristic energy losses of molecular nickelocene. How- 
ever, $\mathrm{C}-\mathrm{C}$ triple bond loss modes are not evident in the spectrum, as is found for nickelocene decomposition on the $\mathrm{Ni}(100)$ substrate. The mode observed at $193.5 \mathrm{meV}$ (1561 $\mathrm{cm}^{-1}$ ) is most likely due to the $\mathrm{C}-\mathrm{C}$ stretch of a carboncarbon double bond only weakly interacting with the surface and thus still containing significant $s p^{2}$ character. Metalvinyl compounds, in which the ligand is $\sigma$-bonded to the metal, are observed near $200 \mathrm{meV}\left(1613 \mathrm{~cm}^{-1}\right)^{19}$ and the $193.5 \mathrm{meV}\left(1516 \mathrm{~cm}^{-1}\right)$ loss is in agreement with the formation of $\sigma$-bonded vinyl and propenyl adsorbate species. The $115.2 \mathrm{meV}\left(929 \mathrm{~cm}^{-1}\right)$ loss is tentatively assigned to the $\nu_{\mathrm{CC}}$ of a single bond from the propenyl species, loss energies from which typically occur in the range of $115-120 \mathrm{meV}$ $\left(927-968 \mathrm{~cm}^{-1}\right){ }^{20}$ The low energy loss at $38.4 \mathrm{meV}(310$ $\mathrm{cm}^{-1}$ ) would then result from the carbon-metal stretch mode.

XPS C $1 s$ data for this system are similar to that for aliphatic carbon, with the binding energy found at $284.5 \mathrm{eV}$. Upon warming to $273 \mathrm{~K}$, all carbon-containing adsorbate species desorb and no carbon can be detected upon this system by AES/XPS techniques. Since ethylene does not adsorb on $\mathrm{NiO}(100)$ unless a significant number of defects are introduced into the system, ${ }^{28}$ these results are consistent with the decomposition of nickelocene into vinylic and propenylic fragments observed in the HREEL spectrum and with their clean desorption as the system is warmed to room temperature.

\section{CONCLUSIONS}

Adsorption of nickelocene on three surfaces with varying reactivity has been studied at $135 \mathrm{~K}$. Nickelocene is molecularly physisorbed on the relatively inert $\operatorname{Ag}(100)$ substrate. The $\mathrm{Ag}(100)$ surface also allows for clean desorption upon heating to $273 \mathrm{~K}$. In contrast, the reactive $\mathrm{Ni}(100)$ surface shows decomposition of adsorbed $\mathrm{NiCp}_{2}$ into acetylene and acetylene-like fragments. Heating of the decomposition products on the surface results in some residual carbidic carbon. Double-bonded carbon containing species such as vinylic and propenylic fragments are observed when nickelocene is exposed to a $\mathrm{NiO}(100)$ surface, and upon heating to $273 \mathrm{~K}$, these species desorb from the substrate. When exposed to large amounts of nickelocene, all three systems formed multilayers of condensed, molecular nickelocene.

\section{ACKNOWLEDGMENTS}

The authors gratefully acknowledge support from the AFOSR under Grant No. F49620-98-1-0463, the Petroleum Research Foundation ACS-PRF 31708AC and the University of Nebraska Center for Materials Research and Analysis.

${ }^{1}$ D. Welipitiya, A. Green, J. P. Woods, P. A. Dowben, B. W. Robertson, D. Byun, and J. Zhang, J. Appl. Phys. 79, 8730 (1996).

${ }^{2}$ D. Welipitya, C. Wadfried, P. A. Dowben, I. Goblukoglu, and B. Robertson (unpublished).

${ }^{3}$ W. W. Pai, J. Zhang, J. F. Wendelken, and R. J. Warmack, J. Vac. Sci. Technol. B 15, 785 (1997).

${ }^{4}$ R. Zanoni, M. N. Piancastelli, M. Marsi, and G. Margaritondo, J. Electron Spectrosc. Relat. Phenom. 57, 199 (1991).

${ }^{5}$ F. Thibaudau, J. R. Roche, and F. Salvan, Appl. Phys. Lett. 64, 523 (1994).

${ }^{6}$ L. M. Dyagileva, Russ J. Phys. Chem. 67, 1071 (1993).

${ }^{7}$ H. D. Kaesz, R. S. Williams, R. F. Hicks, J. I. Zink, Y.-J. Chen, H.-J. Müller, Z. Xue, D. Xu, D. K. Shuh, and Y. K. Kim, New J. Chem. 14, 527 (1990).

${ }^{8}$ J. T. Spencer, Prog. Inorg. Chem. 41, 145 (1994).

${ }^{9}$ D. L. Pugmire, C. M. Woodbridge, and M. A. Langell, Surf. Sci. 411, L844 (1998).

${ }^{10}$ D. Welipitiya, C. N. Borca, C. Waldfried, C. Hutchings, L. Sage, C. M. Woodbridge, and P. A. Dowben, Surf. Sci. 393, 34 (1997).

${ }^{11}$ O. Henrion and W. Jaegermann, Surf. Sci. 387, L1073 (1997).

${ }^{12}$ F. Thibaudau, L. Masson, A. Chemam, J. R. Roche, and F. Salvan, J. Vac. Sci. Technol. A 16, 2967 (1998).

${ }^{13}$ M. A. Langell, C. L. Berrie, M. H. Nassir, and K. W. Wulser, Surf. Sci. 320, 25 (1994).

${ }^{14}$ E. R. Lippincott and R. D. Nelson, Spectrochim. Acta 10, 307 (1958).

${ }^{15}$ M. Barber, J. A. Connor, L. M. R. Derrick, M. B. Hall, and I. H. Hillier, J. Chem. Soc., Faraday Trans. 2 69, 559 (1973).

${ }^{16}$ Handbook of X-Ray Photoelectron Spectroscopy, edited by G. E. Muilenberg (Perkin-Elmer Corporation, Eden Prairie, MN, 1979).

${ }^{17}$ J. Lauterbach, M. Wittmann, and J. Küppers, Surf. Sci. 279, 287 (1992).

${ }^{18}$ D. M. Adams, Metal-Ligand and Related Vibrations (St. Martin's Press, New York, 1968), p. 212.

${ }^{19} \mathrm{~K}$. Nakamoto, Infrared and Raman Spectra of Inorganic and Coordination Compounds, 5th ed. (Wiley, New York, 1997), pp. 263, 282.

${ }^{20} \mathrm{~T}$. Shimanouchi, Tables of Vibrational Frequencies, Consolidated Vol. I, NSRDS-NBS 39; Vol. II, J. Phys. Chem. Ref. Data 6, 993 (1977).

${ }^{21}$ F. Zaera and R. B. Hall, J. Phys. Chem. 91, 4318 (1987).

${ }^{22}$ M. A. Smith, S. Sinharoy, and L. L. Levenson, J. Vac. Sci. Technol. A 16, 462 (1979).

${ }^{23}$ M. Bäumer, D. Cappus, H. Kuhlenbeck, H.-J. Freund, G. Wilhelmi, A. Brodde, and H. Neddermeyer, Surf. Sci. 253, 116 (1991).

${ }^{24}$ C. Xu, D. W. Goodman, J. Chem. Soc., Faraday Trans. 91, 3709 (1995).

${ }^{25}$ R. S. Saiki, A. P. Kaduwela, J. Osterwalder, C. S. Fadley, and C. R. Brundle, Phys. Rev. B 40, 1586 (1989).

${ }^{26}$ R. B. Hall, C. A. Mims, J. H. Hardenbergh, and J. G. Chen, ACS Symp. Ser. 482, 85 (1992).

${ }^{27}$ W.-D. Wang, N. J. Wu, and P. A. Thiel, J. Chem. Phys. 92, 2025 (1990).

${ }^{28}$ R. P. Furstenau and M. A. Langell, Surf. Sci. 159, 108 (1985). 